\title{
Una velada desilusión: la Revolución mexicana según Max Aub
}

\author{
CÉSAR NúÑ̃E
}

\begin{abstract}
Resumen: En este trabajo se analizan las interpretaciones que Max Aub, exiliado republicano español en México, ha tenido del fenómeno revolucionario mexicano y se observa cómo, en ellas, Aub reaprovecha distintas tradiciones textuales, literarias, a la hora de comprender el proceso político mexicano. Se atiende tanto a los escritos que Max Aub publicó sobre temas relativos a la Revolución iniciada en 1910 (en particular, la llamada "narrativa de la revolución") como a las anotaciones de los Diarios privados del autor, editados póstumamente, pero cuya publicación estaba, en gran medida, prevista por el propio Max Aub.
\end{abstract}

Abstract: This work analyzes Max Aub's interpretations of the Mexican revolutionary phenomenon. In these interpretations it is possible to see how Max Aub, a Spanish Republican exile in Mexico, brought a number of different textual and literary traditions to bear on his understanding of the Mexican political process. The study focuses on writings that Max Aub published on subjects related to the Revolution that began in 1910 (in particular, the "narrative of the revolution"), as well as the author's notes in his private Diarios [Diaries], which were edited posthumously but whose publication Max Aub had largely foreseen.

Palabras Clave: Representaciones; Exilio español; Max Aub; Diarios; Revolución mexicana.

KeYwords: Representations; Spanish exile; Max Aub; Diaries; Mexican Revolution.

FECHA DE RECEPCión: 11 de octubre de 2014 FECHA DE ACEPTACiÓN: 11 de diciembre de 2014 



\title{
Una velada desilusión: la Revolución mexicana según Max Aub
}

\author{
CÉSAR NúÑ̃z \\ Universidad Autónoma Metropolitana \\ nunezcesar40@yahoo.com
}

El 27 de octubre de 1966 Max Aub estaba de viaje en Europa. Iría, unos días después, a Israel, a donde había sido invitado por la UNESCO para dictar un curso sobre la historia y cultura de México en la Universidad Hebrea de Jerusalén. Pero se encontraba, aún, en París. Allí, según deja constancia en su diario, se encontró con Jaime Torres Bodet. Y anotó:

Torres Bodet, en el Georges V. Mis dudas acerca de lo que tengo que decir en mi curso, acerca de la revolución: la verdad o miento.

-Mienta usted. Sin duda alguna (2002: 273).

Luego, Aub describe la estampa de Torres Bodet, "cansado, en pijama, abatido", y los signos que el mexicano presiente de su muerte cercana (aunque moriría el 13 de mayo de 1974, casi dos años después que Max Aub, fallecido el 22 de julio de 1972). ${ }^{1}$ Pero, desde luego, interesa ahora el breve diálogo citado. Interesa, en primer lugar, porque dice que el curso sería sobre la "revolución"; sin embargo, en su carácter de escritor, Aub trataría más que nada (las notas del período en su diario lo prueban) sobre la "narrativa de la revolución" mexicana. De hecho, del

\footnotetext{
${ }^{1}$ Incluso, ha quedado constancia de que, luego de ese encuentro de 1966 en París, se volvieron a ver en la ciudad de México varias veces. El 30 de abril de 1968, por ejemplo, Max Aub anota en sus Diarios: "Visita a casa de Torres Bodet. Se encuentra mal de salud, delgado, acabado, arrastrando los pies, viejo. Debe de verme más o menos igual (me lleva un año). Muchos libros, mucha gloria y una tristeza infinita de verse acabado por el tiempo. Dos capítulos de sus memorias, acerca de la unEsco. Gentes que conocemos, buenos apuntes de retrato, tristeza de funcionario que se sabe agarrotado por el presupuesto y el desprecio a la cultura de los burócratas y de los norteamericanos, entonces todopoderosos en la onU. Triste tiempo de la Guerra Fría, en espera de la otra, que no veremos. Llueve: humedad, tristeza, desengaño. Queda el arte y la juventud de los demás" (2003: 123). Aún se verían el 24 de enero de 1972, día en el que, en la Embajada de Francia en México, Max Aub fue condecorado con la Ordre des Arts et des Lettres, con el grado de Commandeur (véase Aub 2003: 306-307).
} 
desarrollo de lo que enseñaría en Israel, del 6 de noviembre de 1966 al 21 de febrero de 1967, Max Aub compondría la Guia de narradores de la Revolución mexicana (Aub 1969) $)^{2}$ y el ensayo sobre "algunos aspectos de la novela de la Revolución mexicana” (Aub 1971) 3 que escribió con el apoyo de una beca de la Fundación Guggenheim y que publicó en 1969 y 1971 respectivamente. ${ }^{4}$ Sea como sea, esta "mixtura", este deslizamiento, entre el hecho histórico y su representación literaria, nada sorprendente para un lector que conozca su obra; dice mucho sobre las dificultades, las "trampas" diríamos, que enfrenta quien quiera analizar cómo Aub veía la Revolución mexicana. ${ }^{5}$

En segundo lugar, interesa, obviamente, el diálogo en sí. Max Aub le propone a Torres Bodet dos posibilidades ("la verdad o miento"), y Torres Bodet elige la mentira. Puede llamar la atención la preferencia,

${ }^{2}$ Hay una reedición de este libro en la colección Lecturas mexicanas que auspició la Secretaría de Educación Pública de México (Aub 1985), y también puede consultarse el texto, recopilado en los Ensayos mexicanos de Max Aub (1974: 87-115), volumen póstumo.

${ }^{3}$ También se encuentra recopilado entre los Ensayos mexicanos (Aub 1974: 31-86).

${ }^{4}$ Incluso José Ramón López García, que accedió a los papeles personales del autor en la Fundación Max Aub, se refiere a "dos cursos sobre literatura mexicana" dictados por Aub en la Universidad Hebrea de Jerusalén, lo que incrementaría aún más, si se quiere, la extrañeza de la alusión del escritor, en 1966, a un curso "acerca de la revolución”. Anota López García: "La documentación y fondo epistolar conservados en el Archivo-Biblioteca de la Fundación Max Aub permite reconstruir con bastante exactitud los preparativos y estancia de Max Aub en Israel. Comisionado por la UNEsCo dentro de su proyecto Oriente-Occidente, impartió dos cursos sobre literatura mexicana en la Universidad Hebrea de Jerusalén y actuó como asesor en el trabajo de organización de un futuro Departamento de Estudios Latinoamericanos y de su Biblioteca" (n. 2).

${ }^{5}$ Sobre este vaivén, esta comunicación fluida entre los órdenes de lo literario y lo extraliterario, en la percepción aubiana de la narrativa en general, pero - más específicamente - también de la "novela de la Revolución", considérense (además de la concepción misma del proyecto de estudio de esa literatura en base a los hechos históricos referidos en ella) afirmaciones como las siguientes: "La narrativa de la Revolución mexicana debe su originalidad [...] a la violencia, a la extensión geográfica e histórica de los hechos, al idioma - y por consiguiente al estilo-, al estar en contra activamente del estado de hecho imperante con el país." (Aub 1974: 34; subr. en el orig.); "[...] lo cierto es que existe una narrativa de la Revolución mexicana. La razón es sencilla; hay que buscarla en los hechos mismos. Hubo novela y revolución porque no fue una revolución sino varias, al mismo tiempo y sucesivas y los grupos en el poder se sucedieron con suficiente tiempo para permitir exilios de pocos ańos, y que, en general, no fusilaron intelectuales sino coroneles y generales; lo que permitió que los escritores tuvieran tiempo de expresar sus rencores y publicarlos" (34-35). 
sin duda, pero llama más la atención el hecho de que verdad y mentira se presentan en la nota como dos discursos que los interlocutores conocen, identifican perfectamente. Y no importa tanto el grado de fidelidad que el pasaje tenga respecto del diálogo efectivamente sostenido, sino la manera en que se lo representa. Ambos saben qué es lo que llaman verdad y qué es lo que llaman mentira. Hay una suerte de código compartido, de "entre nos" que los vincula y que les permite remitirse a dos versiones, opuestas pero igualmente estables, de la Revolución.

Es posible seguir, en las notas del diario personal de Max Aub, esa suerte de "entre nos" que el pasaje citado trasunta. Un entendimiento tácito conecta a Torres Bodet y Aub en el breve diálogo, en el que la mentira se propone como la mejor opción — casi la única, a los ojos de Torres Bodet- ${ }^{6}$ La lectura del fragmento hace casi inevitable preguntarse, en una lógica tan binaria como la que propone, qué es mentira y qué es verdad. Y así, la misma privacidad del diálogo —en la que la opción se discute, en la que se "planea" mentir al hablar de la Revolución - invita a entender que la verdad es sólo una posibilidad "privada”; por lo tanto, la mentira será el discurso público, y ya no sólo de Aub. Si la mentira es un discurso estable, reconocible, ha de tratarse de un discurso público sobre la Revolución, lo que llamaríamos el discurso "oficial".

El doble ámbito que se produce con la escisión moderna de las esferas de lo privado y lo público, por lo demás, no deja de presentar conflictos, vías de comunicación y mezcla, cuyas consecuencias la sociedad de masas muestra de modo constante. La publicación de diarios personales, cartas privadas, a menudo expone un sujeto que se hallaba

\footnotetext{
${ }^{6}$ Por lo demás, es de notar que el diálogo mismo entre Torres Bodet y Aub es posible, entre otras cosas, merced a la creciente conflictividad política mexicana, que estallaría dos años más tarde: "1966 es un año de cambios importantes para Aub: dimite como director de Radio UNAM en solidaridad con el rector de la máxima casa de estudios por las protestas estudiantiles. Pero a la renuncia le siguen nuevos nombramientos. En julio, Francia lo nombra, a través del ministro de Estado de Asuntos Culturales -André Malraux - miembro de la Orden de las Artes con el grado de oficial. Tras este importante nombramiento, en el transcurso de los próximos dos años se llevan a cabo dos viajes de gran importancia para el curso del pensamiento en el exilio de Max Aub: el primero es el viaje a Jerusalén invitado por la unEsco. Tiene como objetivo difundir la cultura española y ayudar a que las relaciones hispanoamericano-israelíes favorezcan la paz a través de cursos y conferencias. La estancia ocurre del 1 de noviembre de 1966 hasta el 20 de febrero de 1967" (Pontón: 56).
} 
velado, oculto bajo la figura pública. En ocasiones, es el individuo el que realiza lo que podríamos llamar "confesiones públicas", por medio de las cuales dialoga con la imagen social que cree se le atribuye y, con frecuencia, la pretende rectificar. Ya que las instancias de enunciación de las subjetividades públicas y privadas son aparentemente tan diversas, siguen lógicas discursivas tan distintas, no es sorprendente que las representaciones que se inscriben en cada una de ellas sean si no contradictorias, al menos difíciles de conjugar, de poner en coherencia. La lectura, de maneras más o menos explícitas, tiende a atribuir la idea de desvelamiento, de verdad, a las representaciones privadas, como si, detrás de la máscara de la imagen pública, se encontrara el "verdadero" sujeto, lo que "en verdad es"; como si —en fin— la imagen privada no fuera otra máscara, ni más ni menos verdadera que aquella otra expuesta a sus contemporáneos. Este rasgo, esta atribución, es sin duda también una característica de la modernidad que ha escindido ambas esferas.

En esa lógica, entonces, Max Aub y Jaime Torres Bodet compartirían un discurso privado que adoptaría la forma de lo verdadero, de la verdadera visión sobre la Revolución, pero, a la vez, dirían en público aquello en lo que no creen. Sus afirmaciones públicas sobre el tema serían parte de la mentira. Y, de hecho, en ocasiones, así fue entendida la posición pública de Max Aub en la política mexicana del siglo Xx. Sebastiaan Faber, por ejemplo, interpreta las prácticas políticas y culturales de los exiliados españoles en México como una colaboración con el régimen priista. En especial, a Max Aub le echa en cara lo que llama su "lealtad al Partido Revolucionario Institucional". Verdaderamente interesado en analizar la labor cultural de Max Aub y otros exiliados españoles como una suerte de "defección" (un abandono de la noción de intelectual crítico republicano y su reconversión en la de peón del liberalismo autoritario), Faber señala que esa "lealtad al PRI" no debe ser entendida —o disculpada, por así decir — como aquella que un desterrado pueda tener con el gobierno que le salvó la vida y le dio refugio: "It has been argued that the Spaniards' allegiance was really confined to the legendary figure of Lázaro Cárdenas, their immediate benefactor. This is true, but only to a certain extent; after all, by the time the Spaniards arrived, Cárdenas's term was practically over" (Faber: 249). ${ }^{7}$

${ }^{7} \mathrm{Al}$ analizar el prólogo a la antología Poesía mexicana (1950-1960) de Max Aub (1960), James Valender (2005) ha comentado este modo de criticar las prácticas cul- 
Sorprende un tanto que Faber, dedicándose al análisis de fenómenos culturales, desestime de modo tan mecánico, a partir de una excusa tan banal como el calendario, el poder de las representaciones. Puesto que resulta notorio que el hecho de que los españoles iniciaran su exilio

turales de los exiliados españoles. El comentario de Valender resume perfectamente la serie de problemas que se esconden bajo la aparente ortodoxia marxista de Faber: "[Faber] no toma suficientemente en cuenta las circunstancias muy particulares en que Aub, lo mismo que sus paisanos, pasó los largos años del exilio. En primer lugar, hay que recordar que su situación como español acogido a la hospitalidad de México habrá pesado mucho sobre su conciencia, y no sólo a la hora de preparar la antología. ¿Cómo no iba Aub a tener presente la generosidad de un país que le había ayudado a escapar de los campos de concentración y que le había dado la posibilidad de rehacer su vida profesional en condiciones de relativa paz y tranquilidad? Por otra parte, la tesis de Faber parece suponer la existencia (por muy clandestina que fuera) de un auténtico movimiento revolucionario, bien organizado y con amplio apoyo popular, preparado para tomar el poder en México en cuanto se presentara la oportunidad. Y este simplemente no era el caso. Si el Partido Revolucionario Institucional, por algún motivo, perdiera el control de la situación, la única alternativa real (y de ello Aub, como los demás republicanos españoles, tenía que darse cuenta) era el ejército. Por lo tanto, no había que hacer olas...” (253-254). En efecto, la ausencia de alternativas al régimen priista sería una evidencia para los exiliados espańoles, conocedores como eran de su propia historia. Más aún, en el caso particular de Max Aub, cuyo interés por la política internacional es evidente, no pasaría desapercibida la situación latinoamericana, caracterizada en esos años por la sucesión de golpes militares cuyas características son de todos conocidas. Valender, además, intentando comprender, más que juzgar, agrega: "de todos modos, no creo que Aub haya tenido que incurrir en ninguna hipocresía para encabezar su prólogo con las palabras ya citadas", que son un elogio de la situación social en México. "En primer lugar, resulta evidente que sí tenía verdadera admiración, si no por todos los cambios que la Revolución mexicana había traído, sí por las conquistas más importantes que ella había supuesto: desde el reparto de la tierra y el incipiente desarrollo industrial, hasta el programa de alfabetización y la integración de las clases más marginadas a una cultura nacional. Desde luego, se tuvo que pagar un precio para conseguir esos cambios, pero los cambios en sí representaban logros que el propio Aub, como muchos mexicanos, no estaba dispuesto a despreciar. Desde luego, el régimen priista de los ańos 40 y 50 no era perfecto, pero de todos modos había logrado importantes avances en materia social para la mayor parte de la población mexicana. De hecho, los terribles conflictos de finales de la década siguiente, no serían entendibles sin el notable crecimiento económico y sin las prestaciones del estado de bienestar disfrutados en los años 50. Porque fueron precisamente ese crecimiento económico y estas prestaciones los que, ya a mediados de los 60, animaron a los elementos más progresistas de la sociedad mexicana a exigirle al gobierno cambios equivalentes en el ámbito político destinados a reforzar la democracia y las libertades individuales; cambios que el régimen político no quiso concederles, y de ahí la terrible masacre de Tlaltelolco de 1968. Y, claro está, en 1960 Aub no tenía por qué prever lo que iba a pasar unos ocho años más tarde” (254). 
cuando ya casi comenzaba el gobierno de Manuel Ávila Camacho no impide que la figura de Lázaro Cárdenas haya sido determinante para la configuración de una imagen de México y de la Revolución mexicana (e incluso, más aún, esa "lealtad" a la figura de Lázaro Cárdenas a pesar del tiempo transcurrido durante los años del exilio, podría ser leída como una opinión política sobre las administraciones de los presidentes que siguieron, como un modo velado de opinar sobre los sucesores). Así lo ha demostrado Francie Cate-Arries (2000), quien, en un trabajo de enorme interés, aludiendo al libro de Edmundo O'Gorman, analiza la "invención de México" por parte de los exiliados republicanos. ${ }^{8}$ CateArries muestra el modo en que México es construido como una utopía política, en la que, merced a su proceso revolucionario, se realiza todo aquello que la España franquista obtura. Los exiliados — dice— "much like their Spanish predecessors of long ago, similarly create a notion of Mexico as an 'ideal place'. But instead of being constituted as a trope of 'El Dorado', or 'the Empire', as desired by the Spanish explorers, Mexico is construed as a political utopia. Specifically, the exiled writers portray Mexico as the perfect reflection of their own defeated Republic, imbued with their own progressive ideals of liberty and justice for all" (227). Así, en el juego de espejos en el que los exiliados españoles observan el México revolucionario y la República española - recurrente, según la autora-, el primero es pensado como la realización de aquello que fue interrumpido en la segunda: "They perceive in the image of Cardenista Mexico the most faithful reflection of their own Republican ideals, of their most 'authentic' national identity" (231). De tal manera,

for the Republican exiles in Mexico, the concept they elaborate of "Mexico" serves a key function in their ongoing project to forge a new national definition of "Spain", and of a collective national identity, a shared sense of what it now, in exile, means to be "Spanish". Just as the

${ }^{8}$ Como resume la autora, "I argue that if Mexico as Cortes' Conquered Native Other defined the Spanish nation as Empire in the sixteenth century, four hundred years later post-revolutionary Mexico again functions as a vehicle of self-formation in the imagination of the exiled Spanish writers. The image that the mirror of Mexico reflects back to their hopeful eyes is, as one exile has stated, 'lecciones de independencia' (Sánchez Vazquez, Del exilio 43), political freedom, social justice. The shattered postwar Spanish Republican exile identity seeks re-unification through the Mexican Other, in the revitalizing embrace of a new transnational community of Hispanic solidarity" (225). 
Aztec Mexico conquered by Cortes reflected back to Spain the image of itself as Empire, so too will post-revolutionary Mexico return to the war-exhausted exiles the inspiring image of themselves as they wish to be: the future liberators of dictator Francisco Franco's Spain (228).

Vale decir, los republicanos construyen una imagen de México por medio de una doble contraposición: por un lado, la política mexicana es el reverso perfecto del nacional-catolicismo español; por otro, ellos mismos, los republicanos, son el opuesto del conquistador del siglo XVI - y de Hernán Cortés, en especial: "the indigenous resistance against the Spanish Conqueror of long ago parallels the current struggle between the Republican combatant and the imperialistic, authoritarian, and oppressive character of the Nationalist movement headed by Franco" (231).

Así, las lecturas de la historia de la Conquista que los exiliados traían a cuestas, eran la matriz — una matriz inversa, desde luego- a partir de la cual buscaban definir su posición frente a otro que, ahora, no querían conquistar sino que, esperaban, los conquistara: "Spanish writers who [...] began to write about Mexico under the 'anxiety of influence' of Cortés' chronicles, emerge from the shadow of the Conqueror's tales by formulating an idea of Mexico based on the indigenous models of Cuauhtémoc and Cárdenas" (226).

Esta posición, que Cate-Arries estudia sobre todo en la obra de Juan Rejano, podría ser reconocida sin dificultad en la de Max Aub. Desde luego, en su obra "pública" —aquella que, decíamos, portaría el discurso "mentiroso". Pero también —y entonces los ámbitos de lo privado y lo público se muestran menos claros en sus límites, susceptibles de deslizamientos complejos- podría observarse fácilmente en la obra "privada" de Max Aub. Cuando en noviembre de 1961, en calidad de director de Radio Universidad, se encuentre por primera vez en su vida con Lázaro Cárdenas, a raíz de la grabación de un disco para la serie "Voz viva de México", que el propio Aub había creado, anotará en su diario —el 23 de noviembre - unas emocionadas palabras de admiración:

El general Cárdenas. Nunca había buscado encontrarle —hablarle-. Magnífico de sencillez, de entereza, de organización. Graba el disco para la Universidad. [...] Lee con convicción, cerrando el puńo izquierdo, a compás de las frases, mientras sostiene, con la derecha, las cuartillas. 
Sorprendentemente joven y fuerte, seguro de sí. [...] Más que un gran hombre: recio, de una vez (Aub 2002: 206).

Incluso cuando Aub, en esos mismos textos privados, el 14 de junio de 1961 borronee una dedicatoria (que nunca utilizó, hasta donde sé) en la que se queje de muchos de sus colegas mexicanos, la figura de Cárdenas permanecerá intacta, "a salvo" de la queja, adherida a un sincero agradecimiento:

No dedico esta buena obra ni a Rodolfo Usigli, ni a Xavier Villaurrutia, ni a Salvador Novo, ni a Benito Coquet, ni a José Luis Martínez, ni a Jorge González Durán, ni a Héctor Azar que, habiendo tenido en sus manos tantos teatros oficiales, jamás se les ocurrió estrenar una obra mía (lo que nada les hubiera costado).

No me puedo enojar con ellos porque son mis amigos y menos todavía porque son mexicanos y si he podido escribir tanto en México, a ellos (al general Cárdenas sobre todo) se lo debo (202).

Quizás esta anotación muestra, como tantas otras, para quien quiera verlo, la mixtura de sentimientos que se entrama en Aub y, en general, en los exiliados. Así, pensar que el ámbito de lo privado es el propio de la "verdad" y el de lo público el de la "mentira" se muestra casi imposible. Implicaría reducir, en principio, el discurso "oficial”, público, sobre la Revolución, a una sola cosa, homogénea y estable. Pero también obligaría a aceptar —y esto acaso resulte más difícil- que la percepción de un sujeto del fenómeno revolucionario, y de México en general, fue unívoca. Si en cualquier caso parecería una idea extraña, en el de Aub, no sólo resultaría inverosímil, sino refutable. Pues, en el mismo ámbito privado, en los mismos Diarios de Max Aub, encontramos textos que, por el contrario, ponen en crisis la posibilidad de pensar una perspectiva única sobre la Revolución.

Dos breves notas privadas, tomadas en abril de 1964, sobre la "influencia de la mariguana [sic] en la Revolución mexicana" dejan constancia de ese entrelazado de miradas al fenómeno. Aub plantea el tema en la primera de ellas, del 27 de abril:

De la influencia de la mariguana en la Revolución mexicana. Si no es por ella, no se explican los triunfos de Villa que aseguran, por lo menos, la victoria de la destrucción - y de la reconstrucción. Los yaquis, lleva- 
dos a donde sea —al este, al sur — regresan a su norte, por la mariguana. Los "dorados", todos mariguanos -Villa, mariguano (no se explican de otra manera sus victorias de Torreón y Zacatecas, las auténticas victorias de la revolución, y la derrota de Celaya porque F. Ángeles, que no era mariguano, debió de cansarse de ayudar mariguanos por muy bien intencionados que estuvieran). El que la mariguana tenga su lugar glorioso en "La cucaracha" es justo. La mariguana es un elemento decisivo del triunfo de la Revolución mexicana. No le levantaron un monumento, tampoco a Villa. Es una lástima, sería rendir a lo irracional pleitesía de razón... (2002: 246).

La segunda, del 30 de abril, continúa la reflexión, mostrando la incertidumbre del sujeto a la hora de evaluar los resultados del proceso revolucionario:

Sigue la mariguana: el PRI es una superestructura de la Revolución mexicana dedicada a escribir —es un decir — la historia de la Revolución mexicana; a fabricarla según las necesidades de sus dirigentes; es decir, según lo que éstos creen necesario, para llevar a los mexicanos hacia metas que consideran — tal vez con razón — favorables. De ahí el rigor o las gracias otorgadas a figuras oscuras, la elevación prestada a segundones, el intento de borrar lo que hoy consideran inadecuado a sus fines. Funciona aquí mejor que en otras partes gracias a la maquinaria extraordinaria del PRI, hijo, en parte, de la mariguana y los "dorados" de Francisco Villa. "Por el momento" no hay nada que decir (246-247).

Emergen aquí las vacilaciones entre el reconocimiento de la operación política que el Estado realiza sobre los sucesos históricos y el de su eventual funcionalidad o conveniencia. Por lo demás, la ambigüedad de la última oración, que entrecomilla el circunstancial, es evidente. Parece imposible resolver en qué sentido "por el momento" no hay nada que decir. ¿Alude a que él, como exiliado, aún nacionalizado mexicano, no cuenta con las condiciones de enunciación que le permitirían hablar del tema en el ámbito público? ¿Es simplemente una referencia al hecho de que las circunstancias referidas, "por el momento", no han cambiado?

Sea como sea, distintas representaciones sobre el mismo objeto se alternan en el mismo espacio discursivo (en este caso, en los diarios personales). Pero, de manera correlativa, similares representaciones se tras- 
ladan de un sitio a otro. La deriva de imágenes contrastantes, entonces, no dependería de la esfera de enunciación en la que se encuentren. El paso de algunos textos "privados" al ámbito público, en efecto, es un fenómeno nada infrecuente en la obra de Aub. Así, por ejemplo, algunos comentarios publicados sobre las relaciones entre narrativa de la Revolución y vida política de los escritores, provienen, casi intactos, de notas de sus diarios. En su ensayo sobre la "novela de la revolución", dice que "todavía es pronto para dar un panorama completo de la narrativa de la Revolución mexicana” y lo atribuye a que

debido a lo relativamente exiguo de las minorías gobernantes muchos de los escritores que tuvieron una actitud crítica para con la Revolución, de 1910 a 1940, acabaron, por un imperativo que les honra, sirviendo al Gobierno cuando éste fue expresión de la mayoría de sus facciones. Los unos, atemperándose a las circunstancias, rectificaron no poco de las primeras ediciones de sus obras mientras alguno, llevado por elemental decencia, como Mariano Azuela, renunció a publicar sus últimos escritos por estar cobrando un sueldo del Gobierno; otros, al estar directamente a su servicio sencillamente se han negado a publicar o aun a reeditar alguno de sus libros (Aub 1974: 52).

Sin la mesura que la edición promovía, sin la omisión de los nombres elididos, encontramos casi la misma afirmación en una nota del 8 de noviembre de 1966, mientras dictaba su curso en Israel:

Algunos novelistas de la Revolución mexicana (Martín Luis Guzmán, Vasconcelos) han modificado los textos de sus "novelas" a medida de las reediciones por la sencilla razón de que no eran novelistas y tuvieron que atemperarse a los vaivenes de la política. No sucedió igual con Azuela, primero porque era novelista y luego porque era una persona decente: murió pobre.

Martín Luis quitó lo dicho acerca de Vasconcelos, Vasconcelos acerca de todos. Vasconcelos se justificó con la poca vergüenza que le caracteriza; Martín Luis no dijo ni pío (Aub 2002: 276).

No es sorprendente esta reflexión en un escritor como Max Aub, también indeciso entre la intervención pública y la autonomización de su oficio, entre el compromiso social y el artístico. 
Podría pensarse, no obstante, que en verdad lo que sucede es que hay un cambio, un proceso temporal, que lleva a los exiliados de la idealización inicial de un México revolucionario como lugar en el que la utopía política se ha realizado al aparente reconocimiento tácito - que la cita primera demostraría - del discurso oficial, "público", como una mentira. Estas oscilaciones obedecerían a que Aub, como otros exiliados, con el paso del tiempo, en la convivencia con el régimen priista, iría desengañándose. Según esta posible explicación, los años transcurridos cambiarían la percepción de la revolución. Obviamente, esta explicación no podría refutarse: su problema no es ser falsa, sino demasiado general. El paso del tiempo trae no sólo desengaños, sino también cambios. Cambios en las políticas gubernamentales y en las personas (" ¿Quién piensa lo mismo veinte años más tarde?”, como se pregunta Aub [1974: 43]). Es obvio que la adopción de la nacionalidad, en 1955, permite a Max Aub considerar la publicación de un volumen de Cuentos mexicanos (con pilón), en 1959. Subrepticios, es posible reconocer en él reparos al desarrollo de la revolución institucionalizada. El clientelismo político, la introducción de esquemas sociales y económicos estadounidenses, la censura, son algunos de los fenómenos que podrían ser fácilmente rastreados allí. Su composición debe mucho a algunos modelos literarios mexicanos. ${ }^{9}$ La parodia siempre fue un procedimiento privilegiado de ese curioso escritor realista que fue Max Aub. La obra de Martín Luis Guzmán, en especial, el autor "clásico" del género según Aub, ${ }^{10}$ resuena

${ }^{9}$ Juan Carlos Hernández Cuevas ha analizado, en su tesis doctoral (2006), ese vínculo entre los Cuentos mexicanos de Max Aub y la narrativa de la Revolución mexicana (véase también Hernández Cuevas 2005). El interés del trabajo es considerable, aunque - acaso debido al recurso a la obra teórica de G. Lukács - reduzca de una manera excesiva la noción de la representación narrativa de México. Me he referido a los problemas de ese modo exclusivamente "realista" de entender los Cuentos mexicanos de Max Aub en Núńez 2012.

${ }^{10}$ Así lo llama en una anotación hecha en Israel, mientras dictaba su curso, el 12 de noviembre 1966: "La tercera época de la novela de la Revolución, que domina Vasconcelos, ve reverdecer de lo barroco, en el estilo. Las descripciones tienen otra vez la frondosidad del naturalismo que la Revolución (la verdadera) había barrido. Vasconcelos la vivió pero empezó a escribir muy tarde, el treinta y tantos, y a los hechos se les sobreponen los recuerdos y los quiere dejar tal como fueron cayendo en inútiles prolijidades al no contar más que recuerdos personales. / La novela de la Revolución tiene tres estilos: / a) El de Azuela, que la vio sin más amor que el que le despertaba el prójimo. Y es un escritor seco. Corren los años diez. / b) El de Martín Luis Guzmán, de los años veinte, 
en las páginas de los Cuentos mexicanos, trayendo al libro su mirada crítica - esa misma mirada crítica que Aub le atribuye, a finales de los sesenta, a la totalidad de la novela de la Revolución como género-; más aún, en sus propios relatos, esa perspectiva sobre el lapso 1910-1940, Max Aub la extiende al mundo urbano y al período de Ávila Camacho, sutilmente satirizado (véase, por ejemplo, la narración "El chueco", allí incluida [Aub 1964: 85-91]).

Sin duda, esos "cuentos mexicanos", tienen algo en común con el modo de pensar la política mexicana que encontramos hacia 1967, al iniciar la relectura de la "narrativa de la Revolución". En efecto, en ambos casos, el punto de partida de la reflexión es una textualidad. El rechazo de la imagen del conquistador que configura las primeras representaciones de los exiliados (Cate-Arries 2000), se ha transfigurado en la repetición de una práctica crítica sobre la Revolución aprendida en los mismos escritores mexicanos. Esa práctica, claro, era - para alguien como Max Aub- parte de la utopía de una Revolución que (al contrario de la rusa, apagada intelectualmente por el estalinismo) incorporaba la crítica entre sus componentes. De allí el tono amargo de su comentario sobre las labores gubernamentales de los escritores mexicanos. Si la utopía se ha roto, es también porque los novelistas no novelan. ${ }^{11}$

en que la política se lo lleva todo por delante, pero con un respeto total hacia la forma. Es el más clásico. / c) La de Vasconcelos, donde la añoranza y el rencor le llevan de la mano al barroquismo. / Con lo que tenemos, en nada (¿qué son treinta años?), 1916, 1928 , 1934, el nacimiento, vida y muerte de una literatura que merece este nombre" (Aub 2002: 277). Esta división en "épocas", aquí esbozada, permanecerá en su estudio "De algunos aspectos de la novela de la Revolución mexicana" (Aub 1971) y en la Guía de narradores de la Revolución mexicana (Aub 1969), en cuyos textos puede encontrarse la calificación de "clásico" atribuida a uno de los volúmenes más famosos del autor. Refiriéndose al período 1920-1930, escribe Aub que "la figura máxima de la década es Martín Luis Guzmán” y agrega que El águila y la serpiente "es una obra maestra que entreteje los fundamentos del género: relatos, crónicas, impresiones, memorias, que forman un libro clásico en cuanto a fondo y forma” (Aub 1974: 75 y Aub 1985: 18).

${ }^{11}$ Nuevamente, un escritor mexicano parece sugerirle este problema a Max Aub, que el 28 de febrero de 1960 había anotado en sus Diarios: "Condición específica del escritor mexicano: no escribir. (Cuando se especifica ya se sabe: las excepciones confirma la especificación.) Días antes de morir Alfonso Reyes: 'Aquí no quedan más que tres escritores: Artemio [de Valle-Arizpe], usted y yo'. (Dentro de nada ninguno, espero que entonces, por ejemplo, Yáñez y Carlos Fuentes se signifiquen 'excepcionalmente'.) / ¿Por qué no escriben? / a) No les daría para vivir (entonces es preferible hablar y beber). 
La matriz de observación de la Revolución mexicana, entonces, sigue siendo una textualidad: la de los escritores mexicanos. Eso, en gran medida, explica el acuerdo tácito con Torres Bodet y explica el hecho de que, en la nota de 1966, Aub deslice el tema del curso de lo representado a su representación: "revolución" por "narrativa de la revolución". En fin, sobre todo antes de 1968, la "matriz" textual, literaria, estaría determinando la mirada sobre la Revolución mucho más que el paso del tiempo.

Y conviene aclararlo, la oscilación de su mirada no se debe sólo al tiempo. De hecho, habría que preguntarse, al leer el breve pasaje que he citado, a qué llaman Max Aub y Torres Bodet "Revolución". No es claro hasta cuándo podemos hablar de "Revolución". Dos años antes de la noche de Tlatelolco, Aub y Torres Bodet dialogan sobre un proceso cuyo final es incierto, impreciso. Así pues, la "mentira" a la que se refieren ¿es una mentira sobre la guerra revolucionaria o sobre la deriva institucional de la Revolución?

En la Guia de narradores..., Max Aub es más que ambiguo al respecto. Por un lado, la "cronología" de la Revolución que propone se termina en 1940, curiosamente, con la llegada de los exiliados republicanos espańoles. Por otro, no se priva de referirse a la obra posterior a ese año de autores como Juan Rulfo, José Revueltas, etc. Es, me parece, un interesante argumento a favor del análisis de Francie Cate-Arries: llegados los republicanos, la utopía se hace palpable y diluye su efectividad. Al mismo tiempo, la Revolución, reconvertida — de modo paradójico, sin duda - en "permanente", continúa.

Pero hay un último problema a considerar. No es claro que los diarios de Max Aub sean textos rigurosamente privados. Puede observarse la expectativa del autor de que en algún momento sus diarios salgan a la luz. Así, por ejemplo, anota el 17 de febrero de 1964 que, lo que escribe en ese momento, lo hace "para cuando salgan impresas estas palabras", y agrega:

esto que escribo, en el momento en que lo hago, deja de ser mío y su ser no es todavía de los demás; si se publica lo han de juzgar a la luz del día

/ b) Carecen de editores: los que pueden vivir de lo que escriben, escriben (periodistas, etcétera). No hay escritor mexicano con un contrato que le obligue a entregar dos novelas al año. (Carpentier, [ilegible] —sí- aquí.)" (2002: 164). 
en que el lector lo haga. Sólo se juzga el ayer a la luz de cuando sea y con un conocimiento de causa del que carecía el autor. No es justo. Escribir hoy para mañana es una artimaña de Dios. Deberíamos escribir para el ayer, por ejemplo que se enterara Hernán Cortés de lo que han dicho, dicen y dirán de él. No hay justicia posible si hablamos hoy a la luz del futuro. Es pedir demasiado. O entonces hay que inventarlo todo. Y no se puede: el tiempo nos tiene encadenados (2002: 243).

Incluso años antes, en 1959, ya había anotado lo siguiente: “¿Diario? (Busco un título.) Todo es diario. Siempre se escribe lo que a uno se le ocurre, según le ha pasado. O se lo imagina. Que tanto monta. No hay —ahí - idealismo y realismo. ¿Lo hay en algo? Todo es uno: diario" (2002: 151). Y, en efecto, el péndulo entre lo documental y lo imaginativo es una de las características más llamativas de la obra de este escritor que fue Max Aub, un realista que gustaba del juego vanguardista. Sea como sea, es evidente que cuatro décadas antes de que se publicaran, ya preveía la edición de sus diarios. Es, al fin y al cabo, una de las tantas maneras de decir al prójimo algo. Si la literatura es siempre una comunicación diferida, prever la publicación de algún escrito para cuando uno ya esté muerto no es algo tan distinto de esperar apenas unos meses.

Así, después de todo, Aub sí dice lo que calla. Sí publica las objeciones que, "por el momento" (como escribía en su nota de finales de abril de 1964) no pueden manifestarse. Hasta ese punto llega la incertidumbre en la enunciación de un escritor exiliado. Lo privado y lo público desdibujan sus límites. En el sutil paso de uno a otro, si bien no hace explícito en qué consiste la "mentira", deja constancia, en cambio, de un tiempo en que la mentira operaba como un discurso socialmente válido sobre la Revolución. Sí inscribe la comprensiva denuncia de la preferencia de Torres Bodet por la mentira. Sí deja constancia de ese tiempo en el que la enunciación de un escritor que - por más nacionalizado que estuviera - todos seguían considerando extranjero debía plegarse sobre alguna de las versiones estandarizadas. Max Aub encontró, en el discurso del diario, una forma de escapar a este otro "falso dilema” (véase Aub 1948). Una manera de inscribir su posición ante las representaciones sociales. Y de retratar la pugna política y cultural de su época. Nos queda a nosotros, sus lectores forzosamente extemporáneos, seguir las pistas que nos dejó para que releyéramos el pasado. 


\section{BibliografíA}

Aub, Max. "El falso dilema”, en Hablo como hombre, México: Joaquín Mortiz, 1967: 45-54 [publicado originalmente en El Socialista, números 45, 46 y 47 (diciembre 1948, enero 1949 y febrero-marzo 1949): 1-2, 2 у 2, respectivamente. Reproducido en Sala de Espera. Vol. III, número 28 (enero 1951): 3-9].

Aub, Max. Cuentos mexicanos (con pilón). México: Imprenta Universitaria, 1959.

Aub, Max. Poesía mexicana, 1950-1960. México: Aguilar, 1960.

Aub, Max. El zopilote y otros cuentos mexicanos. Barcelona: Edhasa, 1964.

Aub, Max. Guia de narradores de la Revolución mexicana. México: Fondo de Cultura Económica, 1969 (Presencia de México, 4).

Aub, Max. "De algunos aspectos de la novela de la Revolución mexicana”, en Diálogos, México, 7, 1 (enero-febrero 1971): 4-11.

Aub, Max. Ensayos mexicanos. México: Universidad Nacional Autónoma de México, Dirección General de Publicaciones, 1974.

Aub, Max. Guía de narradores de la Revolución mexicana. México: Fondo de Cultura Económica / Secretaría de Educación Pública, 1985 (Lecturas mexicanas, 97).

Aub, Max. Diarios 1939-1952. Edición, estudio introductorio y notas de Manuel Aznar Soler. México: Consejo Nacional para la Cultura y las Artes, 2000 (Memorias mexicanas).

Aub, Max. Diarios 1953-1966. Edición, estudio introductorio y notas de Manuel Aznar Soler. México, Consejo Nacional para la Cultura y las Artes, 2002 (Memorias mexicanas).

Aub, Max. Diarios 1967-1972. Edición, estudio introductorio y notas de Manuel Aznar Soler. México, Consejo Nacional para la Cultura y las Artes, 2003 (Memorias mexicanas).

Cate-Arries, Francie. "Conquering Myths: The Construction of 'Mexico' in the Spanish Republican Imaginary of Exile", en Hispanic Review, 68, 3 (2000): 223-242.

Faber, Sebastiann. Exile and Cultural Hegemony. Spanish Intellectuals in Mexico, 1939-1975. Nashville: Vanderbilt University Press, 2002.

Hernández Cuevas, Juan Carlos. "Los cuentos mexicanos de Max Aub" en CiberLetras, 12 (enero 2005): s. p. Artículo en línea, disponible en <http://www.lehman.cuny.edu/ciberletras/v12/hernandezcuevascorregido.htm $>$.

Hernández Cuevas, Juan Carlos. Los cuentos mexicanos de Max Aub: la recreación del ámbito nacional de México. Tesis de doctorado. Alicante: Departamento de Filología Espańola, Lingüística General y Teoría Literaria, 
Facultad de Filosofía y Letras, Universidad de Alicante, 2006. Hay versión digital disponible en <http://rua.ua.es/dspace/bitstream/10045/7738/1/ tesis_doctoral_juan_carlos_hernandez.pdf $>$.

López García, José Ramón. "Un tiempo de muros, los diarios israelíes de Max Aub”, en Ínsula, LVIII, 678 (junio 2003): 17-20.

NúŃEz, CÉsAR A. "Max Aub, 'La censura' y lo mexicano de los Cuentos mexicanos", en Nueva Revista de Filología Hispánica, LX, 2 (2012): 565-573.

Pontón, Rosa Martha. "Max Aub en México (1942-1972)", en Escritos. Revista del Centro de Ciencias del Lenguaje, 32 (julio-diciembre 2005): 41-63.

Valender, James. "Max Aub y su antología de Poesía mexicana (1950-1960)", en Homenaje a Max Aub. Ed. de James Valender y Gabriel Rojo Leyva. México: El Colegio de México, 2005: 253-280 (Serie Literatura del exilio español, 7). 